irregularly over the surface of the track in a number of small discrete particles of varying size.

In a recent interesting paper, Sackmann, Burwell and Irvine ${ }^{5}$ describe the application of a radioactive method to the measurement of the pick-up of metals. Their results are not directly comparable with ours since they measure the amount of metal which accumulates on the small curved surface of the slider after it has traversed a certain distance; but again the results confirm the observation that metallic adhesion occurs through the lubricant film.

F. P. BowDEN.

A. J. W. Moore.

Council for Scientific and Industrial Research, University of Melbourne. Dec. 1.

1 Bowden and Tabor, Proc. Roy. Soc., A, 169, 391 (1939). ${ }^{2}$ Bowden, Moore and Tabor, J. Appl. Phys., 14, 80 (1943).

selson, Conference on Friction and Surface Finish, Mass. Inst. Tech., 217 (1940).

- Hunter, Churchill and Mears, Met. Prog., 42, 1070 (1942).

s Sackmann, Burwell and Irvine, J. Appl. Phys., 15, 459 (1944).

\section{Raman Spectrum of Quartz}

SINCE quartz is transparent in the ultra-violet, the employment of the powerful technique for Ramaneffect studies developed by Rasetti, in which the 2537 A. radiation from a water-cooled magnetcontrolled mercury arc is the exciter, naturally suggests itself for this crystal. Rasetti's own studies ${ }^{1}$ included quartz, but his exposures were very short (20 min.) and it is therefore not surprising that he recorded only fourteen distinct frequency shifts as against the twenty shifts found earlier by Gross and Romanova ${ }^{2}$ with the $4358 \mathrm{~A}$. radiation of the mercury are as the exciter and exposures of the order of 120 hours. However, by prolonging the exposure with the Rasetti technique to 48 hours for a crystal $15 \mathrm{~cm}$. long, I have recorded a very intense spectrum reproduced herewith, in which no fower than forty-one distinct frequency shifts have been observed and measured. All the twenty-one newly observed frequency shifts are represented by relatively feeble lines and evidently belong to the Raman spectrum of the second order, namely, octaves and combinations of the fundamental frequencies of the quartz lattice. The accompanying table gives the measured frequency shifts in wave-numbers, the relative intensities of the lines being roughly indicated on an arbitrary scale within brackets.

\begin{tabular}{|c|c|c|c|}
\hline $\begin{array}{l}\text { Frequency shift } \\
\text { and strength }\end{array}$ & Assignment & $\begin{array}{l}\text { Frequency shift } \\
\text { and strength }\end{array}$ & Assignment \\
\hline $\begin{array}{rr}127 & (20) \\
145 & (2) \\
207 & (15) \\
267 & (7) \\
319 & (1) \\
358 & (6) \\
395 & (5) \\
404 & (5) \\
453 & (2) \\
467 & (30) \\
480 & (2) \\
500 & (2) \\
520 & (1) \\
546 & (1) \\
585 & (1) \\
645 & (1) \\
670 & (0) \\
696 & (4) \\
727 & (0) \\
794 & (5) \\
805 & (5) \\
834 & (1)\end{array}$ & $\begin{array}{c}E_{1} \\
A_{1} \\
E_{2} \\
E_{1} A_{2}+E_{2} \\
E_{\mathrm{a}} \\
\stackrel{A_{\mathrm{a}}}{\left(B_{2}\right)} \\
E_{1}+E_{3}, 2 E_{2} \\
A_{1}+B_{1} \\
E_{2}+E_{2} \\
E_{\mathrm{a}} \\
A_{3}+E_{2} \\
E_{\mathrm{s}} \\
2 E_{3},\left(B_{\mathrm{g}}\right)\end{array}$ & $\begin{array}{rr}859 & (1) \\
890 & (1) \\
925 & (1) \\
940 & (1) \\
960 & (1) \\
1033 & (1) \\
1065 & (4) \\
1082 & (3) \\
1134 & (1) \\
1160 & (7) \\
1228 & (3) \\
1248 & (1) \\
1276 & (0) \\
1369 & (0) \\
1381 & (0) \\
1429 & (0) \\
1456 & (0) \\
1570 & (0) \\
1610 & (1) \\
1630 & (1) \\
2379 & (1) \\
2430 & (1)\end{array}$ & $\begin{array}{c}B_{3}+E_{3} \\
E_{1}+E_{5} \\
2 A_{3}, 2 B_{2} \\
E_{8} \\
A_{4} \\
E_{7} \\
E_{8} \\
A_{1}+E_{6} \\
A_{1}+E_{7} \\
\\
E_{2}+E_{7} \\
B_{4}+E_{2} \\
B_{1}+B_{4} \\
2 B_{8}, A_{3}+E_{7} \\
2 B_{4}\end{array}$ \\
\hline
\end{tabular}

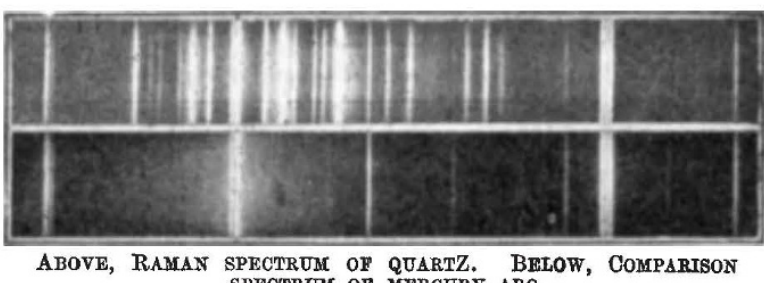
SPEOTRTM OF MERCURY ARC.

According to Bishambar Dayal Saksena ${ }^{3}$, the group of three silicon and six oxygen atoms present in the unit hexagonal cell of the quartz lattice has sixteen distinct fundamental modes of vibration, four of the $A$ class active only in Raman effect, four of the $B$ class active only in infra-red and eight of the $E$ class active in both. The fundamentals shown as such in the table are distinguished by their relatively large intensities, and those of the $A$ class by the strong polarization of the lines. The four fundamental frequencies coming under the $B$ class have been assumed from the infra-red measurements of Plyler ${ }^{4}$ as $B_{1}=$ $385, B_{2}=488, B_{3}=800$ and $B_{4}=1,190$ wavenumbers. The identifications of some of the weaker lines as overtones and allowed combinations are shown in the table, but are only provisional.

Physies Department,

R. S. KRISHNAN.

Indian Institute of Science,

Bangalore.

Feb. 12.

${ }^{1}$ Rasetti, F., Nuovo Cimento, 9, 72 (1932).

${ }^{2}$ Gross and Romanova, Z. Phys., 55, 744 (1929).

${ }^{3}$ Bishambar Dayal Saksena, Proc. Ind. Acad. Sci., A, 12, 93 (1940). - Plyler, Phys. Rev., 33, 48 (1929).

\section{Absorption Spectra of Mercury Halides}

$\mathrm{RAO}^{1}$ has recently observed the absorption spectra obtained when halides of mercury were placed in a heated steel tube. New systems attributed to $\mathrm{HgCl}$ and $\mathrm{HgBr}$ were found and analysed, leading to values for the dissociation energies of these molecules. Comparison of the wave-lengths of these 'new' bands with tables ${ }^{2}$ of collected band heads of known molecules reveals coincidences with $\mathrm{CuCl}$ and $\mathrm{CuBr}$. More detailed comparison shows that Rao's $Q_{1}$ heads of ' $\mathrm{HgCl}$ ' coincide with the $D$ system of $\mathrm{CuCl}$, and the $Q_{2}$ heads with the $E$ system. For ' $\mathrm{HgBr}$ ' all the assigned band heads can be identified with the $B$ system of $\mathrm{CuBr}$; other unassigned bands of ' $\mathrm{HgBr}$ ' coincide with bands of the $A$ system of $\mathrm{CuBr}$. The identity is quite convincing.

In Rao's experiments the copper probably came from the steel tube. I have observed ${ }^{3} \mathrm{CuCl}$ bands in the spectrum of a flame burning in a steel tube. The identification of the emitting molecule of a new band system is not easy, but it is not always realized that impurities as frequently cause trouble in absorption as in emission. It seems desirable to point out incorrect assignments of this type to save later investigators wasting time, and possibly using incorrect data for theoretical work.

\section{A. G. GAYDON.}

Chemical Engineering Department, Imperial College, London, S.W.7.

${ }^{1}$ Rao, A. L. S., Indian J. Phys., 16, 393 (1942).

"Pearse, R. W. B., and Gaydon, A. G., "The Identiflcation of Molecular Spectra" (Chapman and Hall, London, 1941).

'Gaydon, A. G., Proc. Roy. Soc., A, 182, 199 (19t3). 